CORRECTION

\title{
Correction to: Genetic risk of clozapine-induced leukopenia and neutropenia: a genome-wide association study
}

\author{
Jianhua Chen (iD, Ping Yang, Qian Zhang, Ruirui Chen (D), Peng Wang, Benxiu Liu, Wensheng Sun, Xuemin Jian, Siying Xiang, \\ Juan Zhou, Ningning Li, Ke Wang, Chengwen Gao, Yanqin Wen, Chuanhong Wu, Jinmai Zhang, Yalin Zhao, Qiangzhen Yang, \\ Meihang Li, Robert Stewart (iD), Yuanchao Sun, Dun Pan, Yujuan Niu, Zhuo Wang (D), Yifeng Xu (D), Xingwang Li, Lin He (D), \\ Zhiqiang Li (D) and Yongyong Shi iD
}

(C) The Author(s) 2021

Translational Psychiatry (2021)11:34; https://doi.org/10.1038/s41398-021-01484-7

Correction to: Translational Psychiatry https://doi.org/10.1038/ s41398-021-01470-z, published online 3 June 2021

The original version of this article unfortunately contained a mistake. The following authors all contributed equally to this article: Jianhua Chen, Ping Yang, Qian Zhang and Ruirui Chen. We apologize for the mistake. The original article has been corrected.

Open Access This article is licensed under a Creative Commons Attribution 4.0 International License, which permits use, sharing, adaptation, distribution and reproduction in any medium or format, as long as you give appropriate credit to the original author(s) and the source, provide a link to the Creative Commons license, and indicate if changes were made. The images or other third party material in this article are included in the article's Creative Commons license, unless indicated otherwise in a credit line to the material. If material is not included in the article's Creative Commons license and your intended use is not permitted by statutory regulation or exceeds the permitted use, you will need to obtain permission directly from the copyright holder. To view a copy of this license, visit http://creativecommons. org/licenses/by/4.0/.

(c) The Author(s) 2021 